\title{
A LinguAGEM COMO PONTE DE PASSAGEM PARA A "Experiência Superior"
}

\author{
MARIA JOÃO CANTINHO \\ Universidade Clássica de Lisboa \\ Lisboa | Portugal \\ micantinho@gmail.com \\ orcid.org/0000-0003-2509-1351
}

É sobejamente conhecida a influência de Georg von Hamann e da sua filosofia da linguagem na formação do jovem Walter Benjamin. A recusa da instrumentalização da linguagem e a sua concepção da língua pura e messiânica, no texto de 1916, Sobre a Linguagem em Geral e sobre a Linguagem Humana, onde defende a sua crítica à concepção burguesa daquela e recusa a linguagem como médium, nasce de um contexto peculiar que constituirá um dos vectores fundamentais do seu pensamento. Não apenas Hamann se configura como um autor privilegiado, que cita nesse texto, como também bebe em outros autores, como Hermann Cohen, neo-kantiano, e ainda procura nos cabalistas (que conheceu através das traduções de Molitor e Baader) a génese de uma concepção messiânica da linguagem. Neste texto, elenco, não apenas esses autores que marcaram a sua concepção da linguagem, como também o modo como Benjamin integrou essa influência e ela tomou novas configurações no seu pensamento. É na linguagem, na experiência e na história que o jovem Benjamin firma, desde muito cedo, as bases do seu pensamento e da sua obra e estabelece com os seus autores um diálogo, de que se procura aqui dar conta. Porém, o que mais interessa, não é tanto as marcas do seu pensamento, mas sobretudo o modo como essas marcas se inscreveram na singularidade da sua obra. 


\title{
LANGUAGE AS A PASSAGE BRIDGE TO "The Superior Experience"
}

\author{
MARIA JOÃO CANTINHO \\ Universidade Clássica de Lisboa \\ Lisboa | Lisboa | Portugal \\ mjcantinho@gmail.com \\ orcid.org/0000-0003-2509-1351
}

Georg von Hamann's philosophy of language is known to be extremely important in the forming of young Walter Benjamin's thought. The refusal of instrumentalism of language and his concepts of pure and messianic language, in the 1916 text, "On Language as Such and the Language of Man ", when he points his critique of the bourgeois concept and refusal of language as a medium, is created in a particular concept that constitutes one of the main vectors of his thought. Not only does Haman appear as a privileged author, as quoted in the text, but he also borrows from other authors such as Herman Cohen, a NeoKantian, and still searches the genesis of a messianic conception of language in the Kabbalah. In this text appears not only the authors that influenced Benjamin so greatly in the concept of language but also how Benjamin integrated that influence and created new configurations in his thought. It's in language, experience and also history, that young Benjamin sets, since early on, the bases of his thought and of his work, while establishing a dialog with his influencing authors. What matters the most, however, is not so much the marking of his thought, but especially the way the markings are inscribed in the singularity of his work.

Language - Messianism - History - Experience - Translation 
Cada aparição da Natureza era uma palavra, - o sinal, o símbolo e o indício de uma nova, secreta, indizivel e tanto mais profunda reunião, comunicação e comunidade de energias e de ideias divinas. Tudo o que o homem ouviu no começo, viu pelos seus olhos, contempla e o que as suas mãos tocavam, era uma palavra viva; porque Deus era o Verbo.

[Hamann, O Cavaleiro da Rosa-Cruz]

Não é apenas Kant que está muito presente na obra de Benjamin, mas um outro autor que gostaria de ressaltar: Johann Georg Hamann. Pelas razões muito específicas que aqui apontaremos, Hamann tinha sido o próprio mediador (Molder 1992, 120) da edição da Crítica da Razão Pura e começou, de imediato, a preparar uma crítica da própria obra. O seu texto Metakritik über den Purismen der Vernunft (Metacrítica sobre o Purismo da Razão) nunca foi publicado enquanto o autor foi vivo.

Consciente da necessidade de estabelecer os pressupostos da possibilidade do conhecimento, foi na linguagem e no seu uso determinado pela historicidade que Hamann fincou as bases do seu pensamento. Percebendo a relação indissociável e "impura" do pensamento com a linguagem, Hamann compreendeu claramente - como Benjamin terá lido com precisão (Benjamin 1972) - que as leis do pensamento não podiam ser puras. Foi nesta "armadilha" que Kant caiu, na ótica de Hamann.

$\mathrm{Na}$ língua, onde a razão não pode purificar-se, podemos encontrar a história e a situação de todo um povo. Uma conceção da linguagem que, sacrificando em nome da pureza da razão - Hamann referia-se, aqui, a Kant e à sua linguagem exclusivamente científica e separadora -, não tendo em conta estes elementos e enleios através dos quais respira o próprio pensamento e deixando de lado uma parte essencial da experiência humana. Se a língua materna é a matriz, tanto da poesia, como da filosofia e de toda a comunicação entre os homens, como podemos pensar em eliminar a sua equivocidade, a sua impureza, a sua natureza indomesticável e plena de forças e energias imprevistas e imprevisíveis, sem que a destruamos na sua própria essência? Essa parece-nos ser a questão essencial. Existe, tal como uma linguagem comum, uma experiência comum aos homens perpetuada pela tradição. E, tal como acontece no ato poético, só é possível fazer filosofia com a língua materna - traço que distingue naturalmente a filosofia ${ }^{1}$ das outras ciências e que Benjamin abordou com pormenor no "Prefácio" da obra Origem do Drama Trágico Alemão:

É próprio da literatura filosófica o ter de confrontar-se a cada passo com a questão da apresentação [Darstellung]. $\mathrm{Na}$ sua forma acabada, essa literatura apresentar-se-á como doutrina, mas o simples pensamento não tem o poder de lhe conferir esse carácter acabado. A doutrina filosófica assenta na codificação histórica, e por isso não pode ser invocada more geometrico (Benjamin 1972).

\footnotetext{
1 Por isso Benjamin afirma no "Prefácio", que "é próprio da literatura filosófica o ter de confrontar-se a cada passo com a questão da apresentação (Darstellung)". Enquanto a matemática dispensa os problemas da equivocidade da língua materna, já a filosofia e a prosa filosófica são confrontadas a todo o momento com a respiração da linguagem materna (Benjamin 2008, 207).
} 
O que Benjamin afirmou claramente foi a impossibilidade de uma redução da prosa filosófica à linguagem matemática, aquela que já eliminou o problema da apresentação e que pode ser apresentada na sua forma "rigorosamente objetiva" e puramente universal e abstrata. Não é o caso da filosofia, que lida com a linguagem materna. A "codificação histórica de que Benjamin fala" diz respeito à evolução interna da língua e dos conceitos, que escapam sempre à mais acabada definição.

$\mathrm{Na}$ verdade, como diz Maria Filomena Molder, sempre que o filósofo pensa, "pensa sempre numa língua materna ou que foi eleita como tal pela tradição" (Molder 1995, 37). Essa língua materna é a matriz, não apenas da tradição, de que ela se alimenta, como também da própria experiência e do pensamento filosófico. Se a matemática e as ciências exatas podem dispensar a língua materna, devido ao facto de terem criado uma linguagem convencional e rigorosamente objetiva, já a filosofia procura eliminar as imprecisões da linguagem e elevá-la ao rigor que lhe exige o pensamento, lidando com a língua materna.

Que perspetiva da linguagem é a de Hamann e porque exerceu sobre Benjamin tão forte impacto? Seria uma linguagem messiânica, como o pressentiu o jovem Benjamin, que também a procurava no seu texto Sobre a Linguagem em Geral e Sobre a Linguagem Humana (Über Sprache überhaupt und über die Sprache des Menschen)? Referimo-nos, aqui, à procura da linguagem como uma realidade mística e sagrada, misteriosa e mágica ${ }^{2}$, isto é, como metafísica. Ela pode ser tomada, também, como promessa messiânica, como Benjamin definiu posteriormente. ${ }^{3}$ Neste sentido, a linguagem é entendida como uma realidade altamente espiritualizada - e não meramente instrumental - cuja natureza exprime a essência humana, ao mais alto grau.

No ensaio benjaminiano Sobre a Linguagem, Benjamin retomou, por um lado, o pensamento hamanniano e as suas provocações ao pensamento iluminista ${ }^{4}$ e redutor (relativamente à experiência); e, por outro, não se deixou vencer por aquilo a que ele chamou as "teorias burguesas da linguagem", na qual ele identificou um abastardamento da sua essência. Estas são as conceções mais instrumentalizadas da linguagem, que não tomam em consideração a linguagem como essência espiritual e metafísica, precisamente aquela que foi defendida por Benjamin. Foi na ótica de uma conceção metafísica da linguagem, alimentada pelas correntes místicas da tradição mística e da própria cabala, que surgiu o ensaio de Benjamin. No ensaio de Menninghaus (Menninghaus 1980), Walter Benjamins Theorie der Sprachemagie, o autor frisa essa relação entre a cabala e a teoria cabalística da linguagem com o pensamento de Hamann, sobretudo no seu texto Aesthetica in Nuce, cujo subtítulo é "Uma rapsódia em prosa cabalística". Foi neste texto que Hamann expôs as suas

2 “(...) de outra forma dizendo, a imediatez de toda a comunicação espiritual, é o problema fundamental da teoria da linguagem e, se quisermos qualificar de mágica esta imediatez, o problema original da linguagem é a sua magia" (Benjamin 1972, 142-143). Cf. (Benjamin 1993, 126) onde o autor afirma a Martin Buber (carta de junho de 1916): "Mas do ponto de vista da produção de um efeito, quer se trate de literatura poética, profética, objetiva, eu não a posso conceber senão como mágica, ou seja, não-mediatizável'.

3 Também aqui podemos encontrar essa ideia de uma língua messiânica como promessa: "O mundo messiânico é o mundo da atualidade total e integral. Não existe nele senão uma história integral. (...) A sua língua é a própria ideia da prosa, que é compreendida por todos os homens, tal como a língua dos pássaros é compreendida pelas crianças abençoadas ao domingo" (Benjamin 1972, 123).

${ }^{4} \mathrm{O}$ texto de Hamann, O cavalbeiro rosa-cruz, última opinião sobre a origem divina e humana da linguagem, surge como uma crítica ao Tratado sobre a origem da linguagem de Herder. 
ideias sobre a linguagem em geral, de acordo com Menninghaus, ressaltando a forte ligação do autor com a tradição cabalística.

Foi também nesse texto que Hamann falou da linguagem das "coisas" e referiu a linguagem da "natureza", expondo uma visão esotérica e teológica (essa a que nos interessa para compreender a relação com Benjamin). Para Hamann, a linguagem era o verdadeiro fundamento de toda a experiência humana. Por outro lado, Hamann fez uma leitura de Platão que foi partilhada por Benjamin. O âmago da sua leitura do Crátilo (e também a de Benjamin), relativamente à sua teoria da linguagem, recaiu sobre o problema do nome próprio, questão que aparece no texto de Benjamin.

A linguagem é "presença das coisas", é manifestação, fenómeno e, ao mesmo tempo, evidência, que se apresenta mediante imagens, como Hamann explicitou claramente. Campos magnéticos que geram a partir de si forças indomesticáveis e essas imagens são, ao mesmo tempo, esplendorosas na sua evidência e secretas, no modo com que se oferecem ao nosso olhar. Fonte de todo o conhecimento e da própria felicidade humana, essas imagens irradiam em torno de si todo o mistério da Revelação. E, curiosamente, a linguagem não se vislumbra senão no ato de reunir os fragmentos, de coligi-los ${ }^{5}$ e interpretálos.

Foi este extraordinário texto de Hamann que marcou o pensamento do jovem Benjamin, quando redigia o seu texto Sobre a Linguagem em Geral e sobre a Linguagem Humana, como foi também esta experiência metafísica da linguagem em Hamann e a conceção da linguagem como um dom [Gabe] e como Revelação [Offenbarung] (Benjamin 1972, 147), que atraiu o pensamento de Benjamin. Ter-lhe-á permitido repensar o conceito de experiência (Erfabrung) em Kant e reformulá-lo numa tensão para um "nível de experiência metafísica superior". A linguagem é, assim, ao mesmo tempo, o fundamento de toda a razão e de todo o pensamento e tem uma natureza divina, como pura manifestação, como Revelação.

Se, por um lado, referirmos à prioridade genealógica da linguagem, o que lhe confere o seu carácter originário e metafísico, esta revela-se no seu uso materno e que excede as funções lógicas. A ideia de prioridade remete para a apresentação da linguagem na sua natureza imediata e primordial e que antecede o seu uso lógico e instrumental. Esta conceção da linguagem como "prioridade genealógica" - e não lógica, instrumental - marcou o pensamento de Benjamin, que viu nessa consideração de Hamann a possibilidade de se afastar das conceções instrumentais da linguagem, privilegiando-a como uma realidade metafísica e mágica.

Assim, a designada 'prioridade genealógica' da linguagem, antes de ser uma característica da língua achada por dedução ou indução, corresponderia sobretudo ao facto de não conseguirmos conceber, sem ela, nem o pensamento nem a experiência humana. Relembremos que, apesar de não ser este o texto de Hamann que mais importância teve para o texto benjaminiano Sobre a Linguagem, ele continha pressupostos que não podem ser deixados de lado. Também para Benjamin a natureza da linguagem era puramente metafísica, tomada como realidade originária e primeira, no contexto da experiência humana.

\footnotetext{
${ }^{5}$ Referimo-nos à citação em que Hamann diz que nós não podemos usar da natureza mais do que “(...) disjecti membra poetae. Reuni-los é a tarefa do sábio; interpretá-los, a do filósofo (...)”. (Hamann 2001, 18).
} 
$\mathrm{Na}$ correspondência com Scholem, Benjamin falava exaustivamente das suas leituras de Kant e da importância que este autor teve para ele. Numa carta a Scholem (Benjamin 1993, 149-156), datada de Outubro de 1917, ano em que redige Sobre o Programa de uma Filosofia Vindoura (Über das Programm der Kommenden Philosophie), Benjamin esclareceu uma série de questões que eram objeto da sua reflexão, à época. Nessa carta anunciava que ia começar a trabalhar Kant e a história (Benjamin 1993, 158), tendo em vista transformá-lo no objeto de estudo do seu doutoramento ${ }^{6}$. Mais tarde renunciou a esse projeto, como revela a carta a Scholem (Benjamin 1993, 161). E na carta de 23 de Dezembro, dirigida a Scholem, explicou-lhe: "Eu acho as reflexões de Kant totalmente inadequadas para fornecer um ponto de partida ou para constituir, por si próprio, um objeto de estudo". Confessou, na mesma carta, a sua deceção relativamente à leitura de Ideia de uma história universal com um propósito cosmopolita: "No que diz respeito à filosofia da história de Kant, a leitura dos dois principais textos que tratam especificamente dela (...) dececionou as minhas expectativas mais vivas". Essas expectativas tinham claramente a ver com o projeto do seu doutoramento. A razão que Benjamin deu a Scholem para a sua deceção é o facto de que "Em Kant trata-se menos da história do que de certas constelações históricas de interesse ético". Não é a história que se apresenta como objeto fundamental do texto de Kant, mas sim a história subordinada à possibilidade de levar a cabo a ética.

Ainda que Benjamin tivesse retrocedido na sua intenção, relativamente à escolha do tema e do título do seu doutoramento, vemos claramente que o texto Sobre o Programa de uma Filosofia Vindoura se constituiu como uma primeira abordagem da $\left\langle\right.$ tarefa infinita ${ }^{7}$, referida por Kant. Quando redigiu este texto, Benjamin ainda acreditava ser possível constituir a filosofia como um programa filosófico. A sua ideia, a de levar a cabo o trabalho de dissertação sobre o conceito de crítica de arte no romantismo alemão tem que ver com a descoberta do elemento messiânico do pensamento dos primeiros românticos Schlegel e Novalis, abandonando, assim, o projecto de estudar Kant. Qual a preocupação que ocupava o espírito de Benjamin? Como ele escreveu a Scholem, numa carta que lhe dirige em Junho de 1917 (Benjamin 1993, 138), o primeiro romantismo atraía-o por duas razões, de que já falámos aqui: por um lado, porque era o movimento que salvava a tradição no presente e, por outro, porque continha em si o ponto de partida para a constituição de uma perspetiva messiânica da história. Por outro lado, ainda, Benjamin reconhecia a

${ }^{6}$ Inicialmente, Benjamin havia pensado como título do seu doutoramento "A noção de «tarefa infinita» em Kant”. Mais tarde centrar-se-á no estudo do conceito de Crítica de Arte do romantismo, tomando esse tema como objeto do seu doutoramento.

${ }^{7} \mathrm{Na}$ sua obra de 1784, Ideia de uma História Universal com um propósito cosmopolita, Kant desenvolve nove proposições relativas ao desenvolvimento histórico da moralidade humana. $\mathrm{Na}$ oitava proposição, refere-se à história humana no seu conjunto, "como a execução de um plano oculto da natureza a fim de levar a cabo uma constituição estatal interiormente perfeita e, com este fim, também perfeita no exterior, como o único estado em que aquela pode desenvolver integralmente todas as disposições da moralidade humana". Ora, de acordo com Kant, este aperfeiçoamento exigia a infinitude do tempo, daí a razão para falar da história como uma "tarefa infinita" de desenvolvimento da moralidade e do aperfeiçoamento total das disposições humanas. Cf. tradução de Artur Morão. O conceito de "tarefa infinita" é, no entanto, utilizado por Hermann Cohen, na sua obra A Teoria Kantiana da Experiência (Kants Theorie der Erfahrung). A propósito da influência de Hermann Cohen sobre o pensamento benjaminiano, cito a obra de Tagliacozzo (2003). 
importância de $\mathrm{Kant}^{8}$, que assinalava para a metafísica um papel modesto e determinava com precisão (e genialidade) as condições de uma experiência $a$ priori possível. Foi no conceito kantiano de experiência (Erfahrung) que se descobriu uma nova configuração dos fenómenos e do conhecimento, a partir das estruturas transcendentais.

Mas em que consistia a experiência? Proclamando um "retorno a Kant", Hermann Cohen" identificava na filosofia kantiana uma teoria da experiência como conhecimento objetivo. Se Benjamin leu Kant com persistência e atenção, no entanto, a sua leitura foi muito permeável às interpretações de Hermann Cohen, fundador da escola neo-kantiana. $\mathrm{Na}$ primeira edição da sua obra, Hermann Cohen falava desse "retorno a Kant", citando Helmholtz, como um dos grandes espíritos científicos da sua época. Para Cohen, Erfahrung constituía o termo fundamental da filosofia moderna, no sentido em que se afastava de uma abstração e se transformava numa forma de expressão científica, a que importava conceder toda a atenção. Ela cobria tanto o campo da reflexão como o da sensação, tornando-se em simultâneo a "fonte" e o "conteúdo" do conhecimento, o conceito polivalente que designa o "objeto", ao mesmo tempo que designa o "método" (Tagliacozzo 2003, 297$331)$.

Assim, para Cohen, o conceito de experiência transformou-se no núcleo da filosofia kantiana, partindo da separação crítica das esferas da "ciência" e da moral, em que a experiência é identificada com o conceito de conhecimento natural (Tagliacozzo 2003, 297-331). E, neste sentido, o conceito de experiência [Erfahrung] foi subtraído à sua significação vaga e mais habitual, possibilitando, assim, que o criticismo pudesse abrir-se para uma dimensão mais enriquecedora deste conceito. Significava tal, conferir uma dimensão mais objetiva ao conhecimento, delimitada e "reconfigurada" por critérios que the conferem uma maior legitimidade: as condições a priori do conhecimento ou as suas condições de possibilidade.

A teoria kantiana da experiência tinha sido adaptada, na segunda metade do século XIX, aos requisitos da cultura científica dominante, a da interpretação psicofisiológica de Wundt, de Helmholtz. Foi, com efeito, contra este "psicologismo" que a escola de Marburgo e, particularmente Hermann Cohen, se insurgiu, reivindicando a especificidade do método transcendental, face à redução da filosofia kantiana a um papel de auxiliar da ciência experimental.

Existia, ainda, uma outra corrente de retorno filosófico a Kant, na escola que era representada por figuras como Rickert - com quem Walter Benjamin estudou - e Windelband. Esta escola neo-kantiana afirmava uma tendência para alargar o horizonte da teoria kantiana da Erfahrung. É sobretudo sob esta orientação que Benjamin prosseguiu a sua investigação de Kant. Ele desenvolveu a sua crítica ao conceito kantiano de Erfahrung, procurando redescobrir (e alargar) o potencial metafísico de Kant. Na ótica de Benjamin:

\footnotetext{
${ }^{8}$ Relembre-se aqui que, embora Benjamin partilhe alguns aspetos com Hamann, em relação a Kant, no entanto, ele conserva dele a questão da pureza e do a priori, como também conserva a ideia da consciência transcendental, que Hamann rejeita completamente.

${ }^{9}$ É precisamente em 1871 que H. Cohen acaba a sua obra A Teoria Kantiana da Experiência (Kants Theorie der Erfahrung). Scholem e Benjamin frequentaram os cursos de Hermann Cohen em Berlim, antes da Guerra de 14/18.
} 
O problema da teoria kantiana do conhecimento, como de toda a grande teoria do conhecimento, apresenta dois lados e apenas de um deles ele pôde dar uma explicação válida. A primeira é a questão da certeza do conhecimento que permanece; a segunda a da dignidade de uma experiência que foi efémera. Porque o interesse da filosofia é sempre orientado, ao mesmo tempo, para o valor intemporal do conhecimento e para a certeza de uma experiência temporal, considerada como o primeiro, senão o único objeto deste conhecimento (Benjamin 1972, 158).

A questão da permanência do conhecimento derivava de uma outra que é a própria unidade do conhecimento. Se, para Kant, o conceito de experiência tinha o seu suporte na unidade do conhecimento e na consciência transcendental, para Benjamin era preciso encontrar um fundamento que dignifique a experiência, não a reduzindo a um plano meramente científico. Este é o principal obstáculo que Benjamin vê na teoria kantiana: "a realidade na qual o filósofo queria fundar o conhecimento, e com a qual ele queria fundar o conhecimento sobre a certeza e a verdade, é de nível inferior, talvez do último nível" (Benjamin 1972, 158).

Deste modo, a experiência valorizada por Kant era aquela que ia buscar "os princípios da experiência às ciências e sobretudo à da física matemática" (Ibidem). A teoria kantiana do conhecimento, de acordo com a opinião de Benjamin, "satisfazia-se com um conceito pobre de experiência". A razão disso não era especificamente kantiana, mas tinha que ver com a própria visão do mundo [Weltanschaunng], durante a época da Aufklärung (Benjamin 1972, 158159). Tratava-se, com efeito, de aplicar à experiência humana conceitos físicomatemáticos, de ordem quantitativa, um modelo de experiência que, assim, se via reduzido ao modelo da mecânica newtoniana, conceito que era, deste modo, empobrecido, porque era desta forma esvaziado da sua espiritualidade. Não era tanto Kant que Benjamin criticava, mas sobretudo os valores que regiam a sua época e que, assim, determinaram o contexto do pensamento kantiano, incidindo sobre o conhecimento e a experiência.

\footnotetext{
Nos traços que lhe são mais essenciais, ela não se distinguia da dos outros séculos da época moderna. Esta foi, em matéria de experiência ou de visão do mundo, uma das mais pobres. Que Kant tenha podido levar a cabo a sua obra imensa sob o signo da Aufklärung significa que ele partiu duma experiência reduzida ao ponto zero, ao seu mínimo de significação. Pode-se dizer mesmo que a grandeza da sua tentativa, o seu radicalismo particular pressupunha precisamente uma experiência deste tipo, no qual o valor próprio se avizinhava do zero e que não teria podido adquirir uma significação (podemos dizer: uma triste significação) senão acedendo à certeza.

(Benjamin 1972, 159).
}

Ao limitar a importância da metafísica, a época moderna empobrecia claramente a noção de experiência: "Para sugerir o que faz a pobreza e a mediocridade da experiência própria da época, na qual se funda a sua surpreendente leveza metafísica, basta medir a influência limitativa que o conceito inferior de experiência exerceu sobre o próprio pensamento kantiano" (Benjamin 1972, 159). 
Como podemos ver, não é tanto Kant quem era visado na crítica de Benjamin, como ele afirmava: "Kant não contestou nunca a possibilidade da metafísica" (Benjamin 1972, 160). O que Kant pretendia era "estabelecer os critérios que permitem, em cada caso particular, demonstrar esta possibilidade". Era a época de Kant que rejeitava a metafísica, não tinha "necessidade de metafísica" (Benjamin 1972, 159).

Do ponto de vista benjaminiano, apesar de identificar em Kant essa pobreza da experiência, característica da sua época, ele abriu, ao mesmo tempo, o caminho para elaborar os prolegómenos de uma "filosofia vindoura", isto é, abriu o espaço para o verdadeiro conhecimento de uma "experiência superior" (Benjamin 1972, 160). Mas, como Benjamin reconheceu, "para a filosofia vindoura, é da mais suprema importância distinguir e separar os elementos do pensamento kantiano que devem ser assumidos e conservados, os que devem ser revistos e os que devem ser rejeitados" (Benjamin 1972, 159).

Se a filosofia vindoura era possível, Benjamin não poderia ser mais claro: "[...] trata-se, ao mesmo tempo, de formular a exigência principal dirigida à filosofia presente e afirmar a possibilidade de a satisfazer: a exigência, no quadro da tipologia kantiana, de fundar em termos da teoria do conhecimento um conceito superior de experiência" [sublinhado nosso]. (Benjamin 1972, 160).

$\mathrm{E}$ acrescentou que "a filosofia que nós esperamos deveria, justamente, ligar-se à tarefa de descobrir e iluminar claramente uma certa tipologia capaz de fazer justiça a um modo de experiência superior [böhern Erfahrung]".

Por outro lado, a crítica de Hamann a Kant, a Metacrítica, fizera já notar a Benjamin a insuficiência do conceito kantiano de experiência. O Mago do Norte fornecia, em contrapartida, um modelo gnosiológico de recuperação dos componentes suprimidos pela teoria de conhecimento de Kant - com a sua cisão inconciliável entre entendimento e sensibilidade - essas "passagens" ignoradas por Kant e que "proíbem o conhecimento teórico sobre aquilo que vai além do sensível e do âmbito da razão" (Seligmann-Silva 1999, 125-126).

Isto é, Hamann fazia ressaltar a necessidade da metafísica e, para ele, como também para Benjamin, seria a linguagem que comportava uma dimensão modelar de experiência humana e que se sobrepunha certamente às cisões que o sistema kantiano inaugurara. Linguagem tomada como mistério e Revelação, mas também como reflexo da precariedade do conhecimento humano, cheio de lacunas. Se, por um lado, a linguagem apontava para a restauração da unidade, por outro, ela aparecia-nos sempre na sua natureza fragmentária e inacabada.

Se, como vimos anteriormente, a experiência da época kantiana não tinha necessidade de metafísica, porém, tal facto não impediu a possibilidade de abrir uma perspetiva sobre a metafísica futura, que se constitui sobre a base de uma experiência superior. Se Kant havia levado a cabo uma purificação da teoria do conhecimento, "após Kant é possível e necessário encarar como um problema radical" (Benjamin 1972, 163), um novo conceito, "não apenas do conhecimento, mas também e ao mesmo tempo, da experiência, conforme à relação descoberta por Kant entre os dois" (Benjamin 1972, 163). 
Tratava-se, assim, de formular um "novo conceito de experiência que seria fundado sobre novas condições do conhecimento" e que constituiria "o lugar lógico e a possibilidade lógica da metafísica" (Benjamin 1972, 160). A marca decisiva da filosofia vindoura e da sua tarefa "pode ser entendida como a descoberta ou a criação do conceito de conhecimento que, ligando ao mesmo tempo o conceito de experiência exclusivamente à consciência transcendental, torna logicamente possível uma experiência, não apenas mecânica, mas também religiosa" (Benjamin 1972 164).

Ou seja, tomar como base fundamental a consciência transcendenta ${ }^{10}$ que garantiria a possibilidade lógica do conhecimento e da experiência -, mas abri-la também à experiência religiosa e não a limitar ao conhecimento puramente mecânico. Se, já na conceção kantiana, "a lógica transcendental faz aparecer as ideias sobre as quais repousa a unidade da experiência" (Benjamin 1972, 167), um "conceito aprofundado da experiência não se constituirá, como já o dissemos, se não se aliar a continuidade à unidade. É nas ideias que deve revelar-se o fundamento da unidade e da continuidade de uma experiência que não seja nem vulgar nem somente científica, mas sim metafísica. É preciso estabelecer a convergência das ideias no conceito superior do conhecimento". Por isso, a

(...) grande transformação, a grande correção à qual convém submeter um conceito de conhecimento orientado de forma unilateral para as matemáticas e a mecânica não é possível se não se puser o conhecimento em relação com a linguagem, como Hamann havia tentado fazer, mesmo enquanto Kant era vivo (Benjamin 1972, 168).

Assim, a ideia de que o conceito de experiência kantiano devia abrir-se à linguagem - como o havia preconizado Hamann - era a proposta de Benjamin para uma "abertura à experiência superior".

Tendo tomado consciência de que o conhecimento filosófico é absolutamente certo e apriorístico [apriorische], que a filosofia é, por esse lado, igual à matemática, Kant perdeu inteiramente de vista que todo o conhecimento filosófico encontra o seu único meio de expressão na linguagem, e não nas fórmulas e nos números (Hamann 1985, 168)

Só a linguagem, enquanto manifestação da Revelação, apresentando o que de mais sagrado e íntimo existe na natureza humana, permitia o acesso à verdadeira experiência e só ela (a linguagem) podia "afirmar a supremacia sistemática da filosofia sobre todas as ciências" (Benjamin 1972, 168).

\footnotetext{
${ }^{10}$ Kant definiu claramente este tema na sua obra $A$ Crítica da Raz̃ão Pura, ao definir que a unidade sintética da aperceção é o ponto mais elevado ao qual se liga todo o uso do entendimento. Assim, o "eu penso" - a aperceção transcendental - deve poder acompanhar todas as minhas representações e é esta unidade da consciência, a priori, que confere a unidade a todo o conhecimento e à experiência. Contrariamente a Hamann, Benjamin conserva este especto kantiano, que aborda no texto Sobre o Programa da Filosofia Vindoura. Porém, apesar da leitura cuidadosa de Kant, não sabemos até que ponto Kant é filtrado pelos neo-kantianos com quem Benjamin estudou.
} 
Que conceito superior de experiência era este que Kant, apesar de tudo, libertava, e que os neo-kantianos ignoravam? Era a "experiência religiosa e histórica" que se nomeava experiência metafísica. Efetivamente, Kant legava ao presente a possibilidade de um programa filosófico vindouro e dava a Benjamin a oportunidade de reconhecer, ao mesmo tempo, a condição de possibilidade da abertura para uma experiência superior. ${ }^{11}$ Como Benjamin exigia vendo a hipótese de uma "reconstrução" do conceito de experiência, começar por "estabelecer o verdadeiro critério da diferença de valor entre as diversas espécies de consciência, tal será uma das mais elevadas tarefas da filosofia vindoura" (Benjamin 1972, 162). Ou ainda:

\begin{abstract}
É preciso estabelecer como princípio programático da filosofia vindoura esta teoria da purificação da teoria do conhecimento, que se torna possível e necessária de encarar como um problema radical, obter-se-á assim um novo conceito, não somente do conhecimento, mas também e ao mesmo tempo da experiência" (Benjamin 1972, 163).
\end{abstract}

Se bem que às espécies de consciência empírica correspondessem outras tantas espécies de experiência, estas não possuíam senão um valor de imaginação ou de alucinação, precisamente por não ser possível nenhuma relação objetiva entre a consciência empírica e o conceito objetivo de experiência. A experiência que verdadeiramente interessa, segundo ele: "[...] toda a experiência autêntica repousa sobre a pura consciência (transcendental) definida no plano da 'teoria do conhecimento', se 'o termo de consciência ainda é utilizável, uma vez despojado de todo o elemento subjetivo" (Benjamin 1972, 162-163).

Se bem que Benjamin aceitasse, da teoria kantiana, a questão do a priori e a própria consciência transcendental como condição da unidade do conhecimento, rejeitava, no entanto, a diferença entre sujeito e objeto:
A tarefa da futura teoria do conhecimento é de encontrar para o conhecimento uma esfera de total neutralidade em relação aos conceitos de sujeito e de objeto; dizendo de outro modo, trata-se de descobrir a esfera autónoma e originária do conhecimento onde o conceito não define de maneira alguma a relação entre duas entidades metafísicas (Benjamin 1972, 163).

Era a esta unidade da experiência - que não distingue objeto e sujeito que Benjamin chamava a "experiência superior".

Encontrar as condições de possibilidade da experiência na estrutura transcendental do sujeito foi, com efeito, a grande originalidade kantiana, criando um conceito de experiência que se firmou num conhecimento objetivo, já que as condições de possibilidade se configuravam como universais e apriorísticas, no sujeito, garantindo o conhecimento objetivo e dando forma aos fenómenos empíricos a partir do espaço e do tempo. Formas puras e a priori, espaço e tempo conformam todo o dado, unindo-o na consciência do sujeito, conferindo ao conhecimento as suas características essenciais de objetividade e de universalidade e contribuindo, em definitivo, para um novo conceito de experiência. Se Kant nos fornecia a possibilidade de um novo

11 O termo de "experiência messiânica" não aparece no texto, mas ele encontra-se latente nesse anseio de um conceito de experiência superior, que religa história, ciência e religião. Onde encontramos essa fusão entre religião e história, senão na perspetiva messiânica, como Benjamin já havia referido, anteriormente a Carla Seligson? 
conceito de experiência que nos permitia tomá-lo como base de um novo "ponto de abertura para a ideia metafísica da filosofia vindoura" ou um lugar lógico, então compreendemos a intenção benjaminiana de tentar criar um novo programa para a filosofia da história, com base no novo conceito de experiência. Qual a relação entre o conceito de história e de experiência?

Tal como ela aparecia aos olhos de Benjamin, a filosofia da história (tanto a teodiceia quanto a perspetiva positivista da mesma, assente na ideia do progresso) estava agonizante. Não estava só morta, acabada e ultrapassada, mas ela própria tinha o toque petrificador da medusa. Sobretudo a visão historicista do progresso, despojada de religiosidade, alienada na sua visão de um tempo homogéneo e sem possibilidade de renovação, isto é, num tempo irreversível. A possibilidade de encontrar um "lugar" onde assentar um ponto de fissura da história para uma nova visão da mesma, norteada por uma temporalidade messiânica, heterogénea e descontínua, situava-se precisamente no mesmo ponto em que se situava o ponto de abertura para um novo conceito de experiência, na filosofia vindoura. ${ }^{12}$ Se o alargamento do conceito de experiência passa, como Benjamin havia notado, pela "grande transformação, a grande correção à qual convinha submeter um conceito de conhecimento orientado de forma unilateral para as matemáticas e a mecânica", tal não seria possível senão através da linguagem como "ponte de passagem" entre o conhecimento e a experiência.

É a linguagem que confere ao homem e revela a sua essência espiritual e, se como Benjamin pensava, a essência espiritual é idêntica à essência linguística (Benjamin 1972, 142), então a questão crucial do texto Sobre a Linguagem é precisamente o "problema da imediatez de toda a comunicação espiritual, que é o problema fundamental da teoria da linguagem" (Benjamin 1972 142-143), ou seja, o problema original da "magia da linguagem"13.

$\mathrm{O}$ ano de 1915, ano que antecedeu a redação do texto sobre a linguagem foi marcado pelo começo da relação com Gershom Scholem. Foi o ano em que Benjamin retornou a Munique e datou daí, também, o seu interesse profundo pelo romantismo, por alguns textos cabalísticos (é nesta época que conhece, por intermédio de Scholem, os textos de Joseph Molitor e de Franz von Baader) ${ }^{14}$. Gostaríamos de frisar aqui, uma vez mais, o "projeto" benjaminiano - existente no início da sua obra filosófica - entre o texto Sobre a Linguagem (redigido em Novembro de 1916 e anexado numa carta que Benjamin enviara a Scholem) e o texto Sobre o Programa (1917). Se, no texto sobre a linguagem, Benjamin defendia uma conceção metafísica e mágica da

12 Ainda que não refira o termo "messiânico", Benjamin fala sempre de tarefa, de uma metafísica futura, assente num conceito de experiência superior, a qual religa história, ciência, religião. Ora, esse "estado de perfeição moral e ética" que convém à experiência superior, Benjamin já o referiu anteriormente no texto $A$ Vida dos Estudantes. Por outro lado - e isto é uma interpretação nossa - já Benjamin havia preparado este texto com a redação do texto sobre a linguagem, onde aludia claramente a uma conceção da linguagem messiânica.

13 (...) so ist das Urproblem der Sprache ihre Magie” (Benjamin 1972, 143)

${ }^{14}$ Cf. Scholem $(1981,51)$ : «Foi igualmente nesta época [1915] que Benjamin se começou a interessar por Franz von Baader (...) assim como por Franz Joseph Molitor, um aluno de Schelling e de Baader. Molitor era o único autor filosófico de língua alemã digno de ser tomado seriamente, especializado na cabala».

$\mathrm{Na}$ correspondência de Benjamin, sobretudo nas cartas que Benjamin lhe escreve de Dachau, a 23 de Maio de 1917 e em Junho do mesmo ano, respetivamente, podemos ler o extremo interesse de Walter Benjamin pelos textos de Baader e Molitor, mas também pelos românticos Friedrich Schlegel, Novalis, autores que, sem dúvida, estão muito presentes, tanto no estudo da linguagem como da tradução e, ainda, no estudo que publicará sobre o romantismo, O Conceito de Crítica de Arte no Romantismo (Benjamin 1993, 134/139). 
linguagem, foi essa perspetiva sobre a linguagem (já desenvolvida em Sobre a Linguagem em geral e sobre a linguagem humana) aquela que era exigida como ponto de abertura do conceito da experiência e que ele defendia no Programa da Filosofia Vindoura.

Só uma perspetiva metafísica da linguagem, lembremo-nos, pensada à maneira de Hamann, permitia ultrapassar a pobreza do conceito kantiano de experiência, no sentido em que seria uma conceção metafísica da mesma que possibilitaria o alargamento do campo da experiência - que era exclusivamente newtoniana e mecanicista. Se Kant havia "perdido de vista que todo o conhecimento filosófico encontra o seu único meio de expressão na linguagem" (Benjamin 1972, 168), de acordo com Benjamin, então o que se tornava decisivo era introduzir essa correção ou transformação (Ibidem), como Hamann já o havia feito, relativamente a Kant. E esta perspetiva metafísica da linguagem - que Benjamin propôs como correção -, já ele próprio a havia desenvolvido no texto Sobre a Linguagem em Geral e sobre a Linguagem Humana.

A função meramente comunicativa da linguagem e a visão instrumental da mesma, à semelhança da perspetiva mecanicista da experiência e do conhecimento, tal como se apresentavam na época de Kant, são consequências de uma mesma visão do pensamento filosófico da Auflärung. Se o conceito da experiência de Kant enfermava dessa pobreza, como Benjamin o reconhecia, também a teoria da linguagem que refletia o pensamento dessa época era uma "visão empobrecida" da mesma, o que mostrava a necessidade da revisão da "conceção burguesa" da linguagem. Eis que o propósito benjaminiano nos aparece de uma forma muito clara: trata-se de devolver, quer ao conceito de experiência, quer ao da linguagem, uma "experiência superior", isto é, metafísica. Só nas teorias da linguagem, em que ela aparecia como uma realidade metafísica, pôde Benjamin encontrar o fundamento de que necessitava.

Benjamin já conhecia as teorias da linguagem de Hamann, de Humboldt e as conceções místicas sobre a linguagem, tendo-se dedicado à redação do seu texto, a partir do Verão de 1916. Sabemos, pela correspondência de Benjamin entre Buber (Benjamin 1993, 126-127) e Scholem, que o convite de Martin Buber para colaborar na revista Der Jude foi a "provocação" derradeira que deu origem ao texto de Benjamin, onde este expôs a Buber as razões pelas quais não podia concordar com o uso da linguagem como instrumento político (opondo-se ao apelo convicto à participação na Primeira Guerra, feito por Buber e reprovava-lhe que colocasse a escrita ao serviço desse intento). Além de reclamar para a literatura uma séria responsabilidade pela ação e ética humanas, atitude que se consolidou sobretudo após o suicídio de Heinle (por recusa à mobilização da guerra), recusava totalmente a ideia de uma instrumentalização da linguagem ao serviço dos desígnios da política e da guerra. Contrapôs, nesta carta, o carácter instrumental da linguagem, "rebaixada ao nível do puro meio", ao carácter que defende ser o único legítimo: "Do ponto de vista da produção de um efeito, quer se trate de escrita poética, profética, objetiva, eu não a posso conceber senão como mágica, ou seja, não-mediatizável' (Benjamin 1993, 127).

Compreendemos que as sementes foram aqui lançadas, não somente para a constituição de uma teoria da linguagem que "corrigisse" os conceitos 
kantianos de "experiência", mas que também tornasse possível abrir a via para uma metafísica e um plano superior da experiência humana, a partir da correção do conceito kantiano de experiência. A afirmação de uma nova perspectiva da história, ancorada numa nova conceção da linguagem, só podia ter o seu ponto arquimediano numa correção do conceito de experiência formulado por Kant, projeto que abandonou posteriormente. Foi bem essa ideia que Benjamin compreendeu, através da leitura de Hamann e dos primeiros românticos: o sopro de uma visão da história que se abrisse ao religioso e ao metafísico.

A linguagem "só se expressa de modo puro, quando se expressa no nome, quer dizer: na nomeação universal" (Benjamin 1972, 145). Desse ponto de vista - e do ponto de vista da universalidade e da intensidade - a linguagem nomeadora é perfeita e só o homem tem uma linguagem perfeita. Nele, essência linguística e essência espiritual são idênticas e, por essa razão, ela é, ao mais elevado grau, comunicável, na linguagem do nome, pela razão de que "não há um conteúdo da linguagem; enquanto comunicação, a linguagem comunica uma essência espiritual, isto é, comunica pura e simplesmente uma comunicabilidade" (Benjamin 1972 145, 146)

Como referimos, ouvem-se fortemente os ecos de Hamann, particularmente na questão da linguagem enquanto Revelação. Mais uma vez compreendemos a clareza da pretensão benjaminiana: encontrar uma ponte de passagem para a "experiência superior", de que Benjamin nos fala no texto Sobre o Programa da Filosofia Vindoura. Não foi por acaso que Benjamin citou Hamann no ensaio Sobre a Linguagem: "Linguagem, a mãe da razão e Revelação, o seu A e $\Omega$ " (Benjamin 1972, 147). É a "equiparação da essência espiritual e linguística que nos conduz e nos remete para a questão da Revelação. Disse Benjamin que "quanto mais profundo, quer dizer, quanto mais existente e real é o espírito, tanto mais exprimível e exprimido", corroborando o que disse a Buber, afirmando que "se deve eliminar o indizível da linguagem". Contrariando a ideia de uma equivocidade e da "existência de um indizivel" (Benjamin 1993, 126) que se encontra nas teorias místicas da religião, Benjamin afirmou:

(...) o conceito de Revelação quer dizer exatamente isto, se ele tomar a intangibilidade da palavra como a condição única e suficiente e como a caracterização da divindade e da essência espiritual que nela se exprime. O domínio espiritual supremo da religião é (no conceito de Revelação) ao mesmo tempo o único que não conbece o inexprimivel [sublinhado nosso] (Benjamin 1972, 147). 
É no nome que se concentra que se concentra esse poder da Revelação, da pura comunicabilidade. Deste modo (e apesar de o texto $A$ Tarefa do tradutor ter sido redigido anos mais tarde, em 1923), podemos concluir que, já no texto Sobre a linguagem, Benjamin se preocupava com as questões da legitimidade e do princípio da tradução e preparava, neste texto, a sua teoria da linguagem para servir de fundamento a uma teoria da tradução, essa sim, que aparece como uma verdadeira tarefa messiânica - conferindo toda a força ao "projeto" já esboçado em Sobre o Programa da Filosofia Vindoura - e que conduz à língua pura e messiânica. Mas se a expressão de tarefa messiânica não aparecia, no texto Sobre a linguagem, claramente desenvolvida, a teoria da nomeação (enquanto fundamento da linguagem) continha em si o germe de uma tarefa messiânica, que cabe à tarefa da tradução (re)descobrir, restaurando o poder simbólico da linguagem, isto é, o "índice secreto e messiânico" que ela traz em si. É, aliás, esse o significado do último parágrafo do texto de Sobre a linguagem, pois, quando Benjamin fala no residuum da palavra criadora de Deus (Benjamin 1972, 157) que atravessa toda a natureza e a que o nome dá voz enquanto nomeia a coisa, tal nomeação salva-a no conhecimento. Walter Benjamin está, aqui, certamente a falar no sopro de uma língua pura e divina que atravessa toda a natureza e que se diz no homem, no nome, de forma imediata e mágica.

\section{REFERENCIAS}

AGAMBEN, G. La Communauté qui vient: Théorie de la singularité quelconque. (M. Raiola, Trad.) Paris: Seuil, 1990.

AGAMBEN, G. Langue et Histoire. Catégories historiques et catégories linguistiques dans la pensée de Walter Benjamin. Em H. Huisman, Walter Benjamin et Paris. Paris: Éditions du Cerf, 1983.

AGAMBEN, G. Le Langage et la Mort. Paris: Christian Bourgois, 1991.

BENJAMIN, W. «Über das Programm der Kommenden Philosophie». Em W. Benjamin, Gesammelte Schriften (Vols. II, 1). Frankfurt: Suhrkamp Verlag, 1972.

BENJAMIN, W. Briefe I. Frankfurt am Main: Suhrkamp Verlag, 1993.

BENJAMIN, W. Briefe II. Frankfurt am Main: Suhrkamp Verlag, 1993.

BENJAMIN, W. Gesammelte Schriften I, 3. Frankfurt: Suhrkamp Verlag, 1972.

BENJAMIN, W. Über Sprache überhaupt und über die Sprache des Menschen. Em W. Benjamin, Gesammelte Schriften, II, 1. Frankfurt: Suhrkamp Verlag, 1972.

BENJAMIN, W. Ursprung des deutschen Trauerspiels. Em W. Benjamin, Gesammelte Schriften, I, 1. Frankfurt: Suhrkamp Verlag, 1972.

BERMAN, A. L'Áge de la Traduction. Paris: Presses Universitaires de Vincennes, 2008.

BERMAN, A. L'épreuve de l'Étranger. Paris: Flammarion, 1995.

FENVES, P. Arresting Language: From Leibniz to Benjamin. Stanford: Stanford University Press, 2001.

HAMANN, G. V. Aesthetica in Nuce. Paris: Jean Vrin, 2001.

HAMANN, G. V. Metacrítica sobre o Purismo da Razão. In: JUSTO, J. M. Ergon ou Energeia, Filosofia da Linguagem na Alemanha, sécs XVIII e XIX. Lisboa: apáginastantas, 1986.

MENNINGHAUS, W. Walter Benjamins Theorie der Sprachemagie. Frankfurt: Suhrkamp Verlag, 1980 
MOLDER, M. F. A Crítica de Hamann a Kant: O Pensamento a Braços com os seus Sinais de Nascença. In: GIL, F. Recep̧̧ão da Critica da Razão Pura, Antologia de Escritos sobre Kant. Lisboa: Fundação Calouste Gulbenkian, 1992.

MOLDER, M. F. O Pensamento Morfológico de Goethe. Lisboa: INCM, 1995.

MOLDER, M. F. Semear na Neve. Lisboa: Relógio d'Água, 1999.

SCHOLEM, G. Walter Benjamin, Histoire d'une Amitié. (P. K. Errera, Trad.) Paris: Calmann-Lévy, 1981.

SELIGMANN-SILVA, M. Ler o Livro do Mundo. Walter Benjamin: Romantismo e Crítica Literária. São Paulo: Iluminuras, 1999.

SZONDI, P. Espoir dans le passé. À propos de Walter Benjamin. Em P. SZONDI, Poésie et poétiques de la Modernité. Lille: Presses Universitaires de Lille, 1961. pp. 33-48.

TAGLIACOZZO, T. Esperienza e compito infinito nella filosofia del primo Benjamin. Roma: Quodlibet, 2003. 